\title{
25 Research Soure \\ Cellular and Molecular Genetic Analysis of 1980 Male Infertility Patients
}

\section{Meimei Fu}

Affiliated Hospital of Fujian Medical University

\section{Meihuan Chen}

Affiliated Hospital of Fujian Medical University

Nan Guo

Affiliated Hospital of Fujian Medical University

Min Lin

Affiliated Hospital of Fujian Medical University

Ying Li

Affiliated Hospital of Fujian Medical University

Hailong Huang

Affiliated Hospital of Fujian Medical University

Meiying Cai ( $D 22234534 @ q q . c o m$ )

Affiliated Hospital of Fujian Medical University https://orcid.org/0000-0002-7431-2475

Lingpu Xu

Affiliated Hospital of Fujian Medical University

\section{Research}

Keywords: Male infertility, chromosomal abnormality, azoospermia factor microdeletion, oligospermia, cytogenetic analysis

Posted Date: October 12th, 2021

DOI: https://doi.org/10.21203/rs.3.rs-958868/v1

License: (c) (i) This work is licensed under a Creative Commons Attribution 4.0 International License.

Read Full License 


\section{Abstract}

Background The aims of this study were to investigate the distribution of chromosome karyotype abnormality and azoospermia factor (AZF) microdeletion on Y chromosome in male infertility patients and its effect on infertility. Further, the study aimed to guide fertility in patients.

Methods A total of 1980 azoospermic and oligoospermic male infertility patients were selected from the male outpatient department of our hospital from January 2016 to December 2019. Peripheral blood was collected from the patients for karyotype analysis. Further, AZF microdeletion analysis on Y chromosome was performed by capillary electrophoresis.

Results Among the patients of male infertility, 178 had chromosomal abnormality (8.99\%, 178/1980). Among them, 98 had an abnormal chromosome number. Among the 98 patients, 47, XXY was the most common (80 cases), accounting for $44.99 \%$ (80/178) of abnormal karyotypes. There were 211 cases of AZF microdeletion on Y chromosome, with a total deletion rate of $10.66 \%(211 / 1980)$. The most common type was AZFb/c deletion (sY1192 140 cases), accounting for $66.3 \%$ (140/211).

Conclusion Karyotype abnormality and AZF gene microdeletion are important causes of male infertility. Men with Yqh-, del(Y) (q11) have a higher risk of AZF microdeletion. Infertility patients should routinely undergo cell and molecular genetic tests to guide patient fertility.

\section{Background}

Male infertility has been a serious concern in recent years. Statistics showed that up to $15 \%$ of couples of reproductive age were infertile, with males accounting for half of the causes [1-3]. The etiology is very complex, involving various factors, such as genetic factors, endocrine diseases, immune dysfunction, reproductive tract infection or abnormality, sexual dysfunction, and other reasons. Among them, genetic factors account for approximately $20 \%$, which is an important cause of male infertility [4]. Studies have found that the detection rate of chromosomal abnormalities in male infertility patients is $2.2 \%-33 \%$ [5]. $\mathrm{Y}$ azoospermia factor (AZF) is a gene associated with spermatogenesis in region 1 band 1 of the long arm of $Y$ chromosome (Yq11). AZF microdeletion has been reported in $6.6 \%$ of azoospermia and severe oligozoospermia patients [6, 7].

Chromosomal abnormality and AZF microdeletion are important genetic causes of male infertility. Further, they are among the most common genetic abnormalities observed in clinical practice. Etiological examination is helpful for the clinical treatment or assisted reproductive technology to reduce the economic burden of patients. In the present study, karyotype analysis and molecular genetic examination were carried out in 1980 infertile males to investigate the distribution of chromosomal karyotype abnormalities and AZF microdeletion types in male infertility patients.

\section{Materials And Methods}




\section{Clinical data}

A total of 1980 azoospermia and oligospermia male infertility patients, aged $21-56$ years, with a median age of 34 years, were selected from the outpatient department of Fujian Provincial Women's and Children's Hospital from January 2016 to December 2019. This study was approved by the local Ethics Committee. Patients with infertility caused by varicocele, cryptorchidism, vas deferens obstruction, retrograde ejaculation, and urogenital tract infection were excluded. Routine semen analysis was performed according to WHO diagnostic criteria. All the couples had cohabited for more than a year and were not using any form of contraception.

\section{Karyotype analysis}

After the patient signed the informed consent, $2 \mathrm{ml}$ of heparin anticoagulant peripheral blood was extracted. Lymphocyte was cultured for $72 \mathrm{~h}$. Chromosomes and G-bands were prepared for microscopic analysis. The image analysis system of automatic scanning chromosomal microscope GSL-120 was applied to scan images. In each case, 20 karyotypes were counted and 5 karyotypes were analyzed. Cband and $\mathrm{N}$-band were redisplayed as needed, and counting and analysis were increased in case of abnormality. The reference for chromosome nomenclature was based on the International Nomenclature System of Human Cytogenetics 2016.

\section{Molecular genetic analysis - Y chromosome AZF microdeletion detection}

Two milliliters of peripheral blood (EDTA-K2 anticoagulant) of the patient was collected. DNA was extracted using the kit produced by QIAGEN Company, and the DNA content was determined. The AZF detection kit (including 15 sequence tag sites: sY84, sY86, sY88, sY82, sY1064, sY1065, sY127, sY134, sY105, sY121, sY254, sY255ロsY153ロsY1192, and sY160, using SRY and ZFAX/Y sites as internal controls) produced by Shenzhen Yaneng Biotechnology Co., Ltd. was used in accordance with the instructions. Finally, data analysis was performed according to the capillary electrophoresis results. The results were repeated three times.

\section{Results}

\section{Cytogenetic analysis of infertile patients}

Among the 1,980 cases of male infertility, chromosome abnormalities were detected in 178 cases, with an abnormality rate of $8.99 \%$ (Table 1). There were $98,43,25$, and 12 cases of abnormal chromosome number, abnormal structure, polymorphism, and sex reversal syndrome, respectively. Among the 98 patients with abnormal chromosome number, there were 80 cases of Kirchner syndrome, 4 of supermale syndrome, 4 of $48, X X Y Y, 7$ of $45, X / 46, X Y$, and 3 of marker chromosome. The detection rate was the highest for Kreutzfeldt's syndrome. Among 43 cases of chromosomal abnormalities, there were 10 cases of $Y$ inversion, 12 of 46,X,del(Y)(q11), 10 of Robertson translocation, 6 of balanced translocation, and 5 
of 46, XY, inv (9) (p12q13). Among the 25 cases of polymorphism, there were 12 cases of $46, X$, Yqh- $(Y \leq 21)$ and 13 of $46, X, Y q h+(Y>18)$.

\section{Comparison of AZF deletion rates in infertile patients}

Among 1980 male infertility patients, there were 211 cases of AZF deletion on $Y$ chromosome, with a total deletion rate of $10.66 \%$ (211/1980). AZFb/c deletion was found in 140 cases ( $7.1 \%)$. AZFb/c+c was found in 38 cases, accounting for $1.9 \%$. AZFa+b+c+b/c+Sy 160 deletion was found in 12 patients $(0.61 \%)$. AZFb+c+b/c deletion was found in 9 cases $(0.45 \%)$. AZFa deletion was found in 8 cases $(0.4$ $\%)$. AZFb deletion was found in 4 cases (0.2\%) (Table 2).

\section{Infertility patients had both chromosomal karyotype abnormality and AZF deletion}

Among the 1,980 cases of male infertility, 38 cases had chromosomal karyotype abnormality and AZF deletion, accounting for $1.9 \%$ of the total cases. Among them, there were 12 cases with sex reversal syndrome 46, XX and deletion of $A Z F a+b+c+b / c+s Y 160,7$ cases with $46, X, \operatorname{del}(Y)(q 11)$ and deletion of $A Z F b+c+b / c$, and 5 cases with $46, X, \operatorname{del}(Y)(q 11)$ and deletion of $A Z F b / c+c$. There were $46, X Y q h-$ and $\mathrm{AZFb} / \mathrm{c}$ deletions in 4 cases, $46, \mathrm{XYqh}$ - and $\mathrm{AZFb} / \mathrm{c}+\mathrm{c}$ deletions in 2 cases, $46, \mathrm{XY}$ qh- and $\mathrm{AZF}$ a deletions in 1 case, 45,X / 46,XY and AZFb+c+b/c deletions in 2 cases, 45,X/46,XY and AZFb/c+c deletions in 1 case, 47,XXY and AZFb/c deletions in 2 cases, and 46, XYqh+ and AZFb /c deletion in 2 cases (Table 3).

\section{Discussion}

Abnormal chromosome karyotype is one of the most common genetic factors leading to male infertility ${ }^{7}$. In this study, among 1980 male infertility patients, abnormal karyotype was detected in 178, with a detection rate of $8.99 \%$. Among them, 98 had abnormal chromosome number and 80 had $47, \mathrm{XXY}$, accounting for $44.9 \%$ of abnormal karyotype. This is consistent with previous reports $[5,8,9] .47, X X Y$, also known as Klinefelter syndrome, is characterized by congenital testicular hypoplasia, hyaline degeneration of convoluted ducts, and infertility due to no sperm formation [10]. The cause of this disease is that chromosomes do not separate during meiosis. Most of the patients are tall, have a normal phenotype, demonstrate abnormal personality and behavior, and are fertile. A few of them have dysplasia of external genitalia, cryptorchidism, and reduced fertility. The reason for its occurrence is that during the sperm production in the father, $Y$ chromosome does not separate during the second meiosis, resulting in the formation of $24 Y Y$ sperm and the normal ovum $23, X$ after fertilization to form $47, X Y Y$ fertilized ovum. Four cases of $48, X X Y Y$ were found, accounting for $2.2 \%$ of the abnormal karyotype. This karyotype was extremely rare and had two more sex chromosomes than normal males. XXYY might have been formed due to the non-separation of chromosomes during the meiosis of the parents. The severe fibrosis and hyperplasia of testicular tissue in this patient resulted in the thickening of non-specific barrier and the serious destruction of the blood-testicular barrier. Further, this results in serious obstacles and pathological changes in the formation process of spermatogenic cells, which was the main cause of male infertility. 46, X, Inv (Y) (q11) was found in 10 cases, accounting for $5.6 \%$ of abnormal karyotypes. $Y$ 
chromosome inversion may cause the loss of local genes, affecting the development of male gonads and leading to abnormalities such as gonadal dysplasia and infertility [11]. There were 10 cases of Roche translocation, accounting for $5.6 \%$ of the abnormal karyotype. This phenotypic has normal intelligence. However, semen examination showed oligospermia, asthenospermia, and azoospermia. The oligospermia may be related to the abnormal conjunctions during meiosis and the inability to form gametes due to the interference of meiosis test points, which prevents the cells from entering the second meiosis and leads to apoptosis [12]. Sex reversal syndrome was found in 12 cases, accounting for $6.74 \%$ of abnormal karyotypes. The normal male chromosome karyotype is $46, \mathrm{XY}$. Sex reversal syndrome is a kind of disease wherein sex is not consistent with the sex of the chromosome due to abnormal sex determination and differentiation. This type of patient does not have a normal male $Y$ chromosome, has an extra $\mathrm{X}$ chromosome, resulting in testicular tissue dysplasia, thus affecting sperm production.

AZF microdeletions are a common genetic cause of male infertility due to spermatogenic disorders. In this study, 211 cases of AZF microdeletion were detected in 1980 male infertility patients, with a total deletion rate of $10.66 \%$. This result is similar to that reported in several countries in Europe (8-18\%) [13] and South-West Asia (10-16\%) $[14,15]$. In the current research, the most common abnormality is the deletion of sY1192 site in AZFb/c region, accounting for $66.4 \%$ of the total deletion. The second was $\mathrm{AZFb} / \mathrm{C}+\mathrm{C}$, accounting for $18.0 \%$ of total deletion. The sY1192 site is between AZFb and AZFc. The deletion of sY1192 in AZFb/c region belongs to the extended site, which is near AZFc region, and has similar significance to the deletion of AZFc. AZFc deficiency has a variety of clinical manifestations and may appear as normal to oligospermia or azoospermia. For oligospermia patients with AZFc deficiency, their sperm count decreased progressively. Further, their semen should be cryopreserved, which can prepare them for fertility using ISCl-assisted technology. In this study, 12 cases of AZF deletions accounted for $5.7 \%$ of the total deletions, all SRY positive sex reversal syndrome $46, \mathrm{XX}$ male. AZFa deletion is relatively rare, accounting for $3.7 \%$ of the total deletion, which may be related to the large number of cases in this study. The patient presented with sterility due to spermatogenesis disorder due to sertoli-cell-only syndrome (SCOS) and Klinefilter syndrome. Receiving sperm from a donor was the only viable option. In this study, there were 4 cases of simple AZFb deletion, accounting for $1.9 \%$ of the total deletion. AZFb deletion resulted in maturation and development disorders of spermatogonia and primary spermatogonia, presenting as aspermia. AZFb deletion is often accompanied by simultaneous deletion of other regions, with diversified clinical manifestations.

In addition, $Y$ chromosome microdeletions were detected in 7 of 12 patients with 46, X, Yqh -(small $Y$ ), including $4 \mathrm{AZFb} / \mathrm{c}$ deletions, $2 \mathrm{AZFb} / \mathrm{c}+\mathrm{c}$ deletions, and $1 \mathrm{AZFa}$ deletion. $\mathrm{AZFb} / \mathrm{c}$ deletion was detected in 2 of 13 patients with 46, X, Yqh+ (large Y). This suggests that the rate of AZF microdeletion in Yqhchromosome males is higher [16]. Some studies [17-19] believed that the infertility symptoms in patients with large $Y$ chromosomes might not be related to AZF microdeletion. Further, the studies indicated that men with a small $Y$ chromosome had a higher risk of AZF microdeletion. The combination of a small $Y$ chromosome with AZF related region deletion can lead to the mutual deletion of Yq11 euchromatin and Yq12 heterochromatin on $Y$ chromosome, which is more likely to lead to male infertility. In this study, the number of cases with $Y$ chromosome length changes was relatively small. The effect on male infertility 
should be analyzed in a large sample. The change of $Y$ chromosome length has genetic guiding significance for some patients, which should be analyzed in clinical practice. In this study, among 12 46,X,del(Y)(q11) patients, 7 cases had AZFb+c+b/c deletion and 5 cases had AZFc+b/c deletion, indicating that these patients are highly likely to be AZF deficient. Further molecular examination should be performed to confirm it. In the 80 cases of $47, X X Y$, AZF was normal in 78 cases and 2 cases were $\mathrm{AZFb} / \mathrm{csY} 1192$ deletion. There was no significant correlation between azoospermia etiology and AZF microdeletion on $\mathrm{Y}$ chromosome in $47, \mathrm{XXY}$ patients. Therefore, AZF microdeletion testing may not be necessary for $47, \mathrm{XXY}$ patients.

\section{Conclusion}

In conclusion, chromosome karyotype abnormality and AZF microdeletion of $\mathrm{Y}$ chromosome are two major genetic factors causing male infertility. For male infertility patients, regular cell and molecular genetic examination should be carried out to find the cause of male infertility patients. These measures will help the clinical take on corresponding treatment measures or assisted reproductive technology, guide the patient's fertility, and prevent birth defects.

\section{Declarations}

\section{Acknowledg ments}

We thank all participants included in the study.

\section{Funding}

This work was supported by the Fujian Provincial Natural Science Foundation (no. 2017J01238).

\section{Availability of data and materials}

The datasets used and/or analysed during the current study are available from the corresponding author on reasonable request.

\section{Authors' contributions}

Study concepts: LX, HC; Study design: MF; Molecular genetic analysis, MMC; Karyotyping: NG, YL; FISH analysis: $\mathrm{HH}$; Data analysis and interpretation: ML; Statistical analysis:MMC; Manuscript preparation: MC, MF. All authors read and approved the final manuscript.

\section{Ethics approval and consent to participate}

The research was approved by the ethics committee at the Fujian Provincial Maternal and Child Health Hospital, and informed consent was obtained from the patients. 
All procedures involving human participants performed in our study were in accordance with the ethics committee of the Fujian Provincial Maternal and Child Health Hospital. Informed consent was obtained from all individual participants included in the study.

\section{Competing interests}

The authors declare that they have no conflict of interest.

\section{References}

1. Vannapraseuth B. WHO Manual for the Standardized Investigation Diagnosis and Management of the Infertile Male [Book Review]. Australian Institute of Medical Scientists.; 2005.

2. Mehta A, Nangia AK, Dupree JM, Smith JF. Limitations and barriers in access tocare for male factor infertility. Fertil Steril. 2016;105(5):1128-37.

3. Miyamoto T, Minase G, Okabe K, Ueda H, Sengoku K. Male infertility and its genetic causes. J Obstet Gynaecol Res. 2015;41:1501-5.

4. Trieu $\mathrm{H}$, Richard M, Alan T. Selected genetic factors associated with male infertility. Hum Reprod Update. 2002;8(2):183-98.

5. Zhang M, Fan HT, Zhang QS, Wang XY, Yang X, Tian WJ, Li RW. Genetic screening and evaluation for chromosomal abnormalities of infertile males in Jilin Province, China. Genet Mol Res. 2015;14(4):16178-84.

6. Fu L, Xiong DK, Ding XP, Li C, Zhang LY, Ding M, et al. Genetic screening for chromosomal abnormalities and $\mathrm{Y}$ chromosome microdeletions in Chinese infertile men. J Assist Reprod Genet. 2012;29(6):521-7.

7. Esteves SC, Miyaoka R, Agarwal A. An update on the clinical assessment of the infertile male. Clinics. 2011;66(4):691-700.

8. Hargreave TB. Genetic basis of male fertility. Br Med Bull. 2000(3):650-671.

9. Chandley AC. Infertility and chromosome abnormality. Oxf Rev Reprod Biol. 1984;6:1.

10. El-Dahtory F, Elsheikha HM. Male infertility related to an aberrant karyotype, $47, \mathrm{XYY}$ : four case reports. Cases J. 2009;2(1):28-8.

11. Hermetz KE, Newman S, Conneely KN, Martin CL, Ballif BC, Shaffer LG, Cody JD, Rudd MK. Large inverted duplications in the human genome form via a fold-back mechanism. PLoS Genet. 2014;10(1):e1004139.

12. Brugnon F, Janny L, Communal Y, Darcha C, Szczepaniak C, Pellestor F, et al. Apoptosis and meiotic segregation in ejaculated sperm from Robertsonian translocation carrier patients. Hum Reprod. 2010;25(7):1631-42.

13. Imken L, El Houate B, Chafik A, Nahili H, Boulouiz R, Abidi O, et al. AZF microdeletions and partial deletions of AZFc region on the Y chromosome in Moroccan men. Asian J Androl. 2007;9(5):P.674678. 
14. Ambasudhan R, Singh K, Agarwal JK, Singh SK, Khanna A, Sah RK, et al. Idiopathic cases of male infertility from a region in India show low incidence of Y-chromosome microdeletion. J Biosci. 2003;28(5):605-12.

15. Ferlin A, Arredi B, Speltra E, Cazzadore C, Selice R, Garolla A, et al. Molecular and clinical characterization of $Y$ chromosome microdeletions in infertile men: a 10-year experience in Italy. $J$ Clin Endocrinol Metab. 2007;92(3):762-70.

16. Vogt PH, Edelmann A, Kirsch S, Henegariu O, Hirschmann P, Kiesewetter F, et al. Human $Y$ chromosome azoospermia factors (AZF) mapped to different subregions in Yq11. Hum Mol Genet. 1996;5(7):933-43.

17. Choi DK, Gong IH, Hwang JH, Oh JJ, Hong JY. Detection of $Y$ chromosome microdeletion is valuable in the treatment of patients with nonobstructive azoospermia and oligoasthenoteratozoospermia: sperm retrieval rate and birth rate. Kor J Urol. 2013;54(2):111-6.

18. Elfateh F, Dai R, Xin Y, Li L, Liu RZ. Prevalence and patterns of $Y$ chromosome microdeletion in infertile men with azoospermia and oligzoospermia in Northeast China. Iran J Reprod Med. 2014;12(6):383-8.

19. Xiao Z, Zhou X, Xu W, Yang J. A preliminary study of the relationship between the long arm of the $Y$ chromosome (Yqh+) and reproductive outcomes in IVF/ICSI-ET. Eur J Obstet Gynecol Reprod Biol. 2012;165(1):57-60.

\section{Tables}

Table 1 Analysis of abnormal chromosome karyotypes in peripheral blood of 178 male infertility patients (cases) 


\begin{tabular}{|c|c|c|c|}
\hline Classification & Karyotype & Numbers & Percentage \\
\hline \multirow[t]{5}{*}{ Numerical Abnormality } & $47, X X Y$ & 80 & $44.9 \%$ \\
\hline & $47, X Y Y$ & 4 & $2.2 \%$ \\
\hline & $48, X X Y Y$ & 4 & $2.2 \%$ \\
\hline & $45, X / 46, X Y$ & 7 & $4.0 \%$ \\
\hline & $47, X Y,+$ mar & 3 & $1.7 \%$ \\
\hline \multirow[t]{10}{*}{ Structural Abnormality } & $46, X, \operatorname{inv}(Y)(p 11.2 q 11.2)$ & 10 & $5.6 \%$ \\
\hline & $46, X, \operatorname{del}(Y)(q 11)$ & 12 & $6.7 \%$ \\
\hline & $45, X Y, r o b(13 ; 14)(q 10 ; q 10)$ & 6 & $3.4 \%$ \\
\hline & $45, X Y, \operatorname{rob}(14 ; 21)(q 10 ; q 10)$ & 4 & $2.2 \%$ \\
\hline & $46, X Y, t(6 ; 20)(q 21 ; p 13)$ & 1 & $0.56 \%$ \\
\hline & $46, X Y, t(1 ; 11)(q 24 ; q 25)$ & 1 & $0.56 \%$ \\
\hline & $46, X, t(Y ; 15)(q 12 ; p 11.3)$ & 2 & $1.1 \%$ \\
\hline & $46, X Y, t(4 ; 9)(q 25 ; q 33)$ & 1 & $0.56 \%$ \\
\hline & $46, X Y, t(1 ; 7)(q 22 ; p 15)$ & 1 & $0.56 \%$ \\
\hline & 46,XY,inv(9)(p12q13) & 5 & $2.8 \%$ \\
\hline \multirow[t]{2}{*}{ Polymorphism } & 46,XYqh+ & 13 & $7.3 \%$ \\
\hline & 46,XYqh- & 12 & $6.7 \%$ \\
\hline Sex & $46, X X$ & 12 & $6.7 \%$ \\
\hline \multicolumn{4}{|l|}{ Reverse } \\
\hline \multicolumn{4}{|l|}{ Syndrome } \\
\hline Total & & 178 & $100 \%$ \\
\hline
\end{tabular}

Table 2 Results of AZF gene microdeletion detection in 211 cases of $Y$ chromosome 


\begin{tabular}{|c|c|c|c|c|c|}
\hline $\begin{array}{l}\text { Absence } \\
\text { of } \\
\text { Types }\end{array}$ & Numbers & $\begin{array}{l}\text { Constituent } \\
\text { ratio }\end{array}$ & $\begin{array}{l}\text { Miss } \\
\text { Rate }\end{array}$ & STS site & $\begin{array}{l}\text { Clinical } \\
\text { Symptoms }\end{array}$ \\
\hline $\mathrm{AZFb} / \mathrm{c}$ & 140 & $66.4 \%$ & $7.1 \%$ & sY1192 & $\begin{array}{l}\text { Oligospermia } \\
\text { asthenospermia }\end{array}$ \\
\hline $\mathrm{AZFb} / \mathrm{c}+\mathrm{C}$ & 38 & $18.0 \%$ & $1.9 \%$ & $\begin{array}{l}\text { sY153, sY1192, } \\
\text { sY254, sY255 }\end{array}$ & $\begin{array}{l}\text { Oligospermia } \\
\text { asthenospermia }\end{array}$ \\
\hline$A Z F a+b+c+b / c+s Y 160$ & 12 & $5.7 \%$ & $0.61 \%$ & $\begin{array}{l}\text { sY84, sY86, sY88, } \\
\text { sY82, sY1064, } \\
\text { sY1065, sY127, } \\
\text { sY134, sY105, } \\
\text { sY121, sY254, } \\
\text { sY255, sY153, } \\
\text { sY1192 }\end{array}$ & azoospermia \\
\hline $\mathrm{AZFb}+\mathrm{c}+\mathrm{b} / \mathrm{c}$ & 9 & $4.3 \%$ & $0.45 \%$ & $\begin{array}{l}\text { sY127, sY105, } \\
\text { sY121, sY134, } \\
\text { sY254, sY255, } \\
\text { sY153, sY1192 }\end{array}$ & azoospermia \\
\hline AZFa & 8 & $3.7 \%$ & $0.40 \%$ & $\begin{array}{l}\text { sY584, sY86, sY88, } \\
\text { sY82, sY1064, } \\
\text { sY1065 }\end{array}$ & azoospermia \\
\hline $\mathrm{AZFb}$ & 4 & $1.9 \%$ & $0.2 \%$ & $\begin{array}{l}\text { sY127, sY134, } \\
\text { sY105, sY121 }\end{array}$ & azoospermia \\
\hline
\end{tabular}

Table 338 cases with both chromosomal karyotype abnormality and AZF deletion Complex Chromosome Abnormalities AZF microdeletion Numbers Constituent ratio

\begin{tabular}{|c|c|c|c|}
\hline $46, X X$ & $A Z F a+b+c+b / c+s Y 160$ & 12 & 31.6 \\
\hline \multirow[t]{2}{*}{$46, X, \operatorname{del}(Y)(q 11)$} & $A Z F b+c+b / c$ & 7 & \multirow[t]{2}{*}{31.6} \\
\hline & $\mathrm{AZFb} / \mathrm{C}+\mathrm{C}$ & 5 & \\
\hline \multirow[t]{3}{*}{ 46,XYqh- } & $\mathrm{AZFb} / \mathrm{c}$ & 4 & \multirow[t]{3}{*}{18.4} \\
\hline & $\mathrm{AZFb} / \mathrm{C}+\mathrm{C}$ & 2 & \\
\hline & AZFa & 1 & \\
\hline \multirow[t]{2}{*}{$45, X / 46, X Y$} & $A Z F b+c+b / c$ & 2 & \multirow[t]{2}{*}{7.9} \\
\hline & $\mathrm{AZFb} / \mathrm{c}+\mathrm{C}$ & 1 & \\
\hline $47, X X Y$ & $\mathrm{AZFb} / \mathrm{c}$ & 2 & 5.3 \\
\hline $46, X Y q h+$ & $\mathrm{AZFb} / \mathrm{c}$ & 2 & 5.3 \\
\hline
\end{tabular}

